\title{
EL CERRO DE POTOSÍ Y EL DIOS PACHACÁMAC
}

\author{
THE CERRO DE POTOSÍ AND THE PACHACÁMAC GOD
}

\author{
Teresa Gisbert ${ }^{1}$
}

\begin{abstract}
En este trabajo se plantea que el Cerro de Potosí se ocultó a los españoles por ser el santuario más importante de la región, el cual estaba dedicado al dios Pachacámac. Los testimonios que indican que el cerro de Potosí era "Apu" (Cerro o Señor) adorado son abundantes, pero es el cronista Arzans de Orsúa y Vela (año 1736) quien dice que este "Apu" pertenecía a Pachacámac, dios del mundo subterráneo. Una tradición recogida cerca del salar de Uyuni dice lo mismo; finalmente un sacrificio realizado en el siglo XVI a orillas del lago Titicaca en honor a Pachacámac, muestra la presencia de este dios en el Collasuyo. Cuando los incas llegaron a Potosí introdujeron el culto al Sol y cuando llegaron los españoles identificaron el cerro con la Virgen María la cual, a su vez, se identificó con la Pachamama o Madre Tierra.
\end{abstract}

Palabras claves: Apu, huaca, lago Titicaca, Pachamama o Madre Tierra, Collasuyo.

In this essay it is argued that "Cerro de Potosî" was hidden from the Spanish conquerors because it was the region's most important huaca or sanctuary, due to the fact that it was dedicated to the god Pachacámac. Abundant testimonies (colonial documents) indicate that "Cerro de Potosí" was a worshipped "Apu" (Mountain, Señor or Lord), nevertheless chronicler Orzans de Orsúa y Vela (1736) stated that this "Apu" belonged to Pachacámac, god of the underworld. A tradition collected near the Salar de Uyuni states the same; finally, a sacrifice in honor of Pachacámac that occurred during the $16^{\text {th }}$ century on the shores of Lake Titicaca, shows the presence of this god in the Collasuyo. When the Incas reached Potosí, they introduced worship of the Sun, and when the Spanish conquerors arrived, they identified the "Cerro de Potosî" with the Virgin Mary which at the same time was identified with Pachamama or Mother Earth.

Key words: Apu, huaca, Lake Titicaca, Pachamama, Mother Earth, Collasuyo.

Los cronistas nos dicen que el cerro de Potosí era huaca adorada y Arzans de Orsúa y Vela (1965) afirma que esta huaca estaba relacionada con el dios Pachacámac, cuyo santuario principal se encuentra cerca de la ciudad de Lima. Este cerro, como muchos otros, cuando llegan los cristianos se pone bajo la protección de la Virgen María y es identificado con ella.

Estas relaciones son difíciles de explicar pues se basan en la concatenación de hechos separados entre sí por el tiempo y el espacio. Estos hechos nos muestran una lógica basada en similitudes, lógica que no forma parte de la historia sino que es producto de tradiciones susceptibles de ser alteradas a través del tiempo. Sin embargo, son fuentes que nos aproximan a un pasado aún muy difuso.

\section{EI Descubrimiento del Cerro y la Adoración que Recibía}

Capoche (1959 [1585]), que es el cronista más antiguo de Potosí, nos dice:

El primero que dio noticia de él (Cerro de Potosí)..., fue un indio guanca natural de
Jauja, yanacona de Villarroel, que era un español que residía en las minas de Porco.Y antes de éste, el que lo descubrió fue un indio llamado Gualpa de nación Chumbivilca que está en tierra del Cuzco, que yendo por la parte del poniente siguiendo unos venados se le fueron subiendo el cerro arriba, y como... estaba mucha parte cubierto de unos árboles que llaman queñua y de muchas matas...le fue forzoso asirse de una rama que estaba nacida en la veta que (después) tomó nombre de la Rica. Y en la raíz y vacío que dejó conoció el metal

y añade:

Y como viese su extrema riqueza, secretamente labraba la veta sin comunicarlo a nadie hasta tanto que el indio guanca, que era su vecino en Porco, vio (lo) que sacaba...y extrañándolo le preguntó de que mina era... Y tanto le importunó que le hubo de decir lo que pasaba. Ambos pelearon y el guanca avisó a su amo Villarroel (Capoche 1959 [1585]:77).

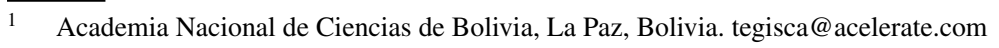


En esta crónica también se asegura que el cerro de Potosí era huaca adorada (Figura 1). El texto es el siguiente:

Más había de doce años que los españoles poseían este reino y no tenían noticia de la riqueza de este cerro, ...y en su descubrimiento (del Potosí) no se halló rastro que los antiguos incas o reyes se hubiesen aprovechado de sus minas, ni se halló señal de labor... ora por alguna vana observancia y ceremonia a que eran inclinados estos indios (adorando los montes señalados y piedras singulares)... dedicándolos a sus huacas o adoraciones, que era el lugar donde el demonio los hablaba y hacían sus sacrificios-... (Capoche 1959 [1585]:77).

Esto se corrobora en tres textos más, una carta de Pablo José de Arriaga S.J. al General de los Jesuitas, un texto de las Relaciones Geográficas de Indias (Jiménez

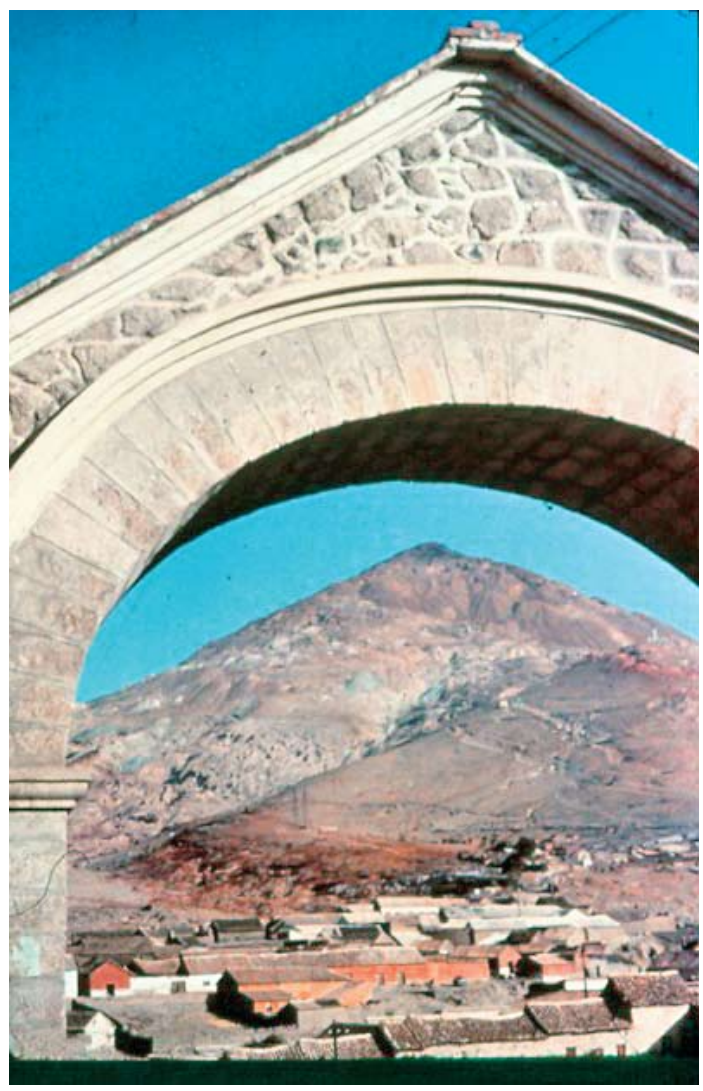

Figura 1. Vista del Cerro de Potosí desde el arco de Cobija. View of Cerro de Potosí from the Cobija ridge. de la Espada 1965) y en La Crónica Anónima de 1600 (Mateos 1944). En la carta del padre Arriaga al General de la Orden de los Jesuitas, Claudio Aquaviva, fechada en Lima en abril de 1599, se dice que los indios de Potosí adoraban a dos cerros: el Cerro de Potosí y el Huayna Potosí. No es extraño que Arriaga se interesara en este hecho pues es autor de La Extirpación de la idolatría en el Perú, libro escrito en 1621.

Una sola cosa diré por haber sido muy pública... poco más de dos millas de esta Villa, en el camino real están dos cerros a que los indios desde tiempo inmemorial han tenido extraña devoción acudiendo allí a hacer sus ofertas y sacrificios y consultando al demonio en sus dudas y recibiendo de él respuestas. Estas dos peñas eran piedras de escándalo, de suerte de que con la ocasión de ellas caían en muchas Idolatrías los indios (Monumenta Peruana 1974:VI 688).

Para impedir esta idolatría Arriaga levantó una pared frente al cerro principal. La pared cayó. Este hecho, que seguramente los indígenas atribuyeron a la fuerza de sus dioses, Arriaga lo explica racionalmente indicando que la pared cayó porque no estaba bien construida. El episodio terminó con la construcción de una capilla: "desterrando el Príncipe del cielo al Príncipe de las Tinieblas". La capilla se puso bajo la advocación de San Bartolomé, apóstol que luchó contra el demonio.

En las Relaciones Geográficas de Indias (Jiménez de la Espada 1965) se lee:

Subió al cerro este dicho indio Gualpa en compañía de otro indio... llegaron ambos indios a lo más alto del cerro de Potosí, el cual cerro tiene una mesa en lo más alto del espacio de cien pies, poco más o menos. Allí hallaron ser adoratorio de los indios comarcanos y haber algunas cosas ofrecidas de poca importancia a la guaca que allí estaba... (Relaciones Geográficas de Indias Jiménez de la Espada 1965 T.I:359).

La Crónica Anónima de 1600 (Mateos 1944) dice:

que en una plaza muy grande que llaman el Rescate del Metal de ordinario pasaban 
de seis o 7 mil indios... y cuando el padre (Barzana) no podía acudir a predicar ... suplía por él el hermano Gonzalo Ruiz, que como vivían entonces en medio de las tinieblas y engañados del común enemigo, no sabían sino adorar guacas y al cerro grande y pequeño que están junto a la villa, llamando al uno Apu Potochi y al otro Guaina Potochi, y tenían mucho cuidado de ofrecerles sacrificios... (Crónica Anónima de 1600 Mateos 1944:T.I.146).

Carmen Salazar-Soler (1997) recoge otros testimonios en su trabajo Las Huacas y el Conocimiento Científico del Siglo XVI que corroboran el hecho de que el cerro de Potosí era huaca conocida. Por ello no es extraño que el descubrimiento se deba a la delación de un indio, pese a que existe una segunda versión, también consignada en el trabajo citado, de que fueron cuatro españoles los que, buscando minas, enviaron a un indio a constatar la existencia de las ofrendas de oro y plata que tenía el cerro en su cima y es así como el indio encontró la veta (Salazar-Soler 1997:252). Tratándose de una huaca tan conocida, como lo fue el Cerro de Potosí, es fácil deducir que estos españoles conocieron la noticia por boca de un indígena.

\section{Pachacámac}

Dado que el Cerro de Potosí era una huaca, es importante determinar a qué dios estaba consagrado. Ocaña supone que estaba consagrado al Sol (de Ocaña 1969:184), información que se recoge en Qaraqara-Charka (Platt et al. 2006:157). Sin embargo, Arzans de Orsúa y Vela relaciona el Cerro de Potosí con el dios Pachacámac. La versión de Ocaña es muy ligera pero fue escrita en 1601, la de Arzans de Orsúa y Vela es más detallada aunque la escribió en 1736. Creo que vale la pena estudiar más a fondo la información de Arzans de Orsúa y Vela pues la tradición que une al Cerro de Potosí con Pachacámac se ha conservado hasta hoy en forma oral. En este trabajo trato de analizar todos aquellos datos que pueden avalar la versión del historiador potosino, sin pretender por ello que la relación Pachacámac-Cerro de Potosí sea confirmada.

Con respecto a que el Cerro de Potosí estuviera consagrado al Sol, es posible que tal ocurriera cuando los incas llegaron a la zona, probablemente crearon un culto paralelo como ocurrió en el valle de Ichma cuando los incas lo conquistaron, pues respetando el culto a Pachacámac levantaron un templo dedicado al Sol y construyeron un acllahuasi y otras dependencias (Eeckhout 2004:496).

Arzans de Orsúa y Vela (1965) nos dice que cuando los indios supieron que el indio Hualca había revelado a los españoles las riquezas del cerro les enviaron un mensaje pidiendo que Hualca les fuera entregado para castigarlo. El texto es el siguiente:

informáronse (los indios) de cómo o quién descubrió el Cerro a los españoles que hasta entonces no lo sabían, y noticiándose de que había sido el indio Hualca con quien ellos habían tenido amistad por ocasión de venir a su laguna o ciénega a dar pasto a los carneros (a quien ellos nombran llamas) se enfurecieron... Y así el indio capitán (cuyo nombre era Chaqui Catari que se interpreta pie de víbora) puesto en pie lleno de ira y rabia dijo: 'Decid a esos enemigos nuestros, ladrones de oro y plata, barbudos sin palabra ... que al mal hombre Hualca, lo ha de castigar el gran Pachacámac, por que les ha descubierto el Potocsi, que a ninguno de nuestros Ingas se lo dio; y que si quieren paz y no guerra que se vayan de aquí y nos entreguen a Hualca para castigarlo en nombre de Pachacámac, y por haber faltado a la orden que nos dio a todos de que no sacásemos la plata del Cerro, cuando se oyó el estruendo, y así que nos lo envíe porque tiene muy enojado a Pachacámac' (Arzans de Orsúa y Vela 1965: TI:39).

Curiosamente Potocsi quiere decir "el que estalla", lo que coincide con el texto que dice "se oyó un estruendo".

Arzans de Orsúa y Vela ve necesario aclarar de qué dios se trata, y añade:

diré que quiere decir Pachacámac. A este adoraban los indios como señor de sus dioses en el Perú a porque sus reyes lo hacían así. Pachacámac se interpreta el que cría y da vida al universo, y era este un ídolo de gran veneración entre los ingas y sus vasallos y a quien le tenían hecho un 
suntuoso templo en el valle de Pachacámac cuatro leguas de Lima.

Las características propias de Pachacámac vienen dadas en el texto de Huarochiri, allí el dios Llocllayhuancupa se expresa así: "Yo soy hijo de Pachácamac, del que hace temblar la tierra". El texto continúa: "la gente decía a propósito del que hace temblar la tierra: cuando se encoleriza (la tierra) tiembla, a veces cuando mueve su cara a un lado tiembla (por eso) no mueve su cara en absoluto si moviera todo su cuerpo el mundo acabaría" (Taylor 1987:295). Calancha con respecto a este dios nos dice: "Pachacámac bramando encendía los andes y centellando atemorizaba los campos" (Calancha 1976: T.III:933).

Pachacámac, además de ser el señor del mundo subterráneo desde donde brotan los temblores y los terremotos, según Calancha también era el dios de las comidas. Al respecto dice María Rostworowski (1992) en el mito de Pachacámac y Vichama, donde Pachacámac es dios de las tinieblas y Vichama es hijo del Sol

Pachacámac, indignado de que un hijo del Sol le quitase la adoración que se le debía rendir solo a él, cogió al recién nacido y sin oír los gritos de la madre, despedazó a la criatura. Luego para que la mujer (su madre) no se quejase por falta de subsistencias, sembró los dientes del infante y de ellos brotó el maíz; de las costillas y huesos surgieron las yucas y todas las de más raíces de la tierra; y de su carne brotaron pepinos, pacaes y demás frutas y árboles. Desde entonces desapareció el hambre; gracias a este suceso reinó la abundancia en la costa y Pachacámac se tornó en dios de las subsistencias (Rostworowski 1992:27).

\section{La Imagen de Pachacámac}

Arzans de Orsúa y Vela nos dice que el año de 1575 se halló dentro del Cerro de Potosí:

una estatua de metales diferentes que medida después tenía siete cuartas y así era del tamaño de un hombre mediano. El rostro tenía muy hermoso (aunque los ojos no estaban bien formados) y era de plata blanca; el pecho hasta la cintura de rosicler; los brazos de diversas mezclas; no tenía forma de pies sino que desde la cintura iba adelgazando hasta rematar en punta, aunque tenía una pequeñita basa; y todo era de metal negrillo" (Arzans de Orsúa y Vela 1965 [1736]: T.I:159).

Extraña figura que podría leerse como un ser mitad humano mitad serpiente. El historiador potosino dice además que:

los españoles quisieron sacarla entera y no pudo ser porque como tenía la cabeza pegada a un gran trozo de metal al cortarlo se quebró el pescuezo. Sacáronla afuera y moviendose un gran alboroto entre los indios comenzaron sus acostumbradas y diabólicas interpretaciones... pues... decían que aquel era el Cerro de Potosí y que ya los españoles le habían quitado la cabeza como lo habían hecho con sus ingas...

y sigue:

bajaron al pueblo esta obra de la naturaleza.

Estamos ante una formación natural que es leída como una deidad. Al encontrarse en el fondo de la mina y tener forma aproximadamente humana es posible que este hallazgo sea el origen del "Tío" que hoy es venerado dentro de las minas y que se representa como un demonio. "Tío" (Figura 2) según Cobo (1956) quiere decir Dios, y así lo explica:

Porque como no tuvieron en su lengua (de los indios) D, sino que en lugar della usaban desta letra T, así, en lugar de decir Dios, suelen pronunciar Tios (Cobo 1956: T.I:155).

Tenemos por una parte la relación del cerro con el dios Pachacámac y por otra una figura, en este caso natural, que tiene una forma que parece humana y que se identifica con el cerro de Potosí. No sabemos si podemos identificarlo también con Pachacámac pues la imagen descrita no coincide con la de Pachacámac que tenía dos rostros, pese a ello nos inclinamos a creer que puede tratarse de este dios que es el único mentado con relación a Potosí. 


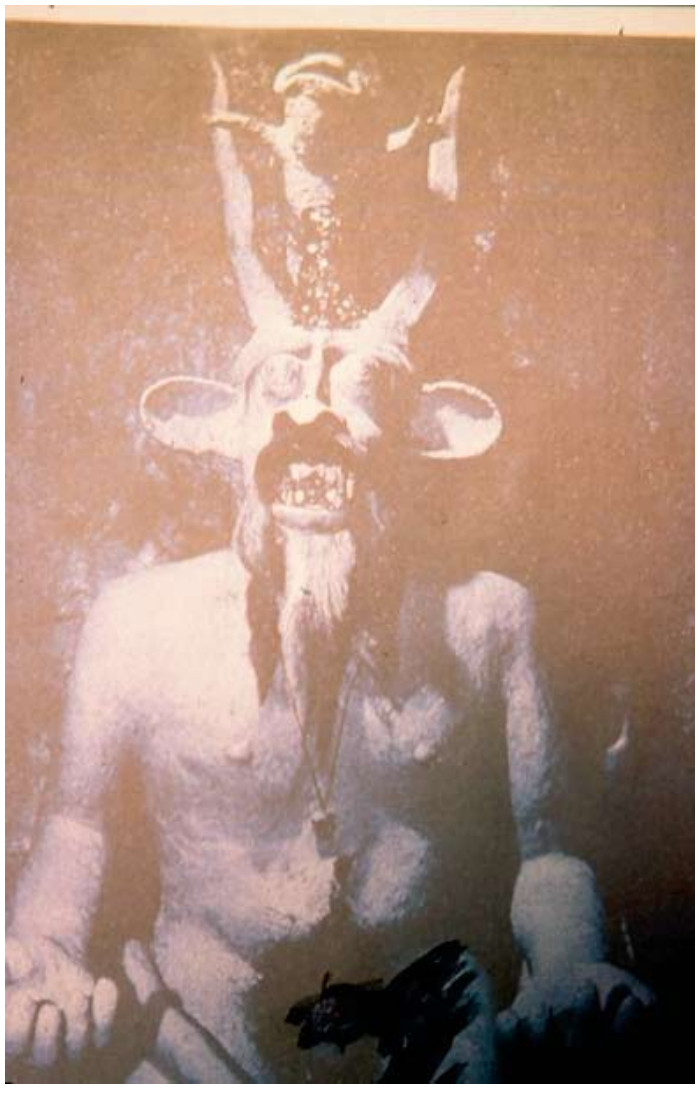

Figura 2. El "Tío" de la mina. The Protector of the mine.

El cerro de Potosí no es el único caso en que un ídolo antropomorfo se identifica con un cerro o " $a p u$ ", el caso de Pucarani es similar. Al respecto Alcedo (1967) en su Diccionario dice, refiriéndose a Pucarani:

pueblo de la provincia del corregimiento de Omasuyos, en el Perú, llamose en tiempos de los indios Quescamarca, que significa lugar de pedernales... los españoles cuando lo poblaron en tiempo del Virrey Don Francisco de Toledo lo llamaron Pucarani, por dar gusto a los indios, en memoria de una fortaleza que tenían a cuatro leguas de allí, para defenderse de los indios Pacajes... adoraban estos gentiles (los de Pucarani) un cerro que sobresale entre los demás de la cordillera y es el inmediato al pueblo, llamado Cacaaca, siempre cubierto de nieve, donde tenían la figura de un indio de piedra, de media vara de alto, sacrificando criaturas para aplacarlo... (Alcedo 1967:241).

Dicho cerro es el actual Huayna Potosí situado en el departamento de La Paz.

Según Menzel (1968) el estilo cerámico encontrado en Pachacámac corresponde a la cultura Huari y por tanto los restos ceremoniales relacionados con Pachacámac deben datarse en el Horizonte Medio, después del siglo VIII de nuestra era y antes del siglo XII. Vale decir, que son anteriores a los incas; estos respetaron el templo de Pachacámac y construyeron otro dedicado al Sol. En el antiguo templo se encontró una imagen bicéfala, tallada en un alto poste de madera. Allí se muestra el anverso y reverso de un mismo ser diferenciado tan solo por sus atributos (Figura 3). En uno de los lados el personaje se viste con mazorcas de maíz, identificables con el día y el sol, concepto que se refuerza con la conquista de los incas (Eeckhout 2004:497). En el otro lado tiene dos peces y en el torso cabezas de zorro, animal relacionado con la noche. Se muestran así las dos fases antagónicas del mito de Pachacámac. Es un dios con doble rostro.

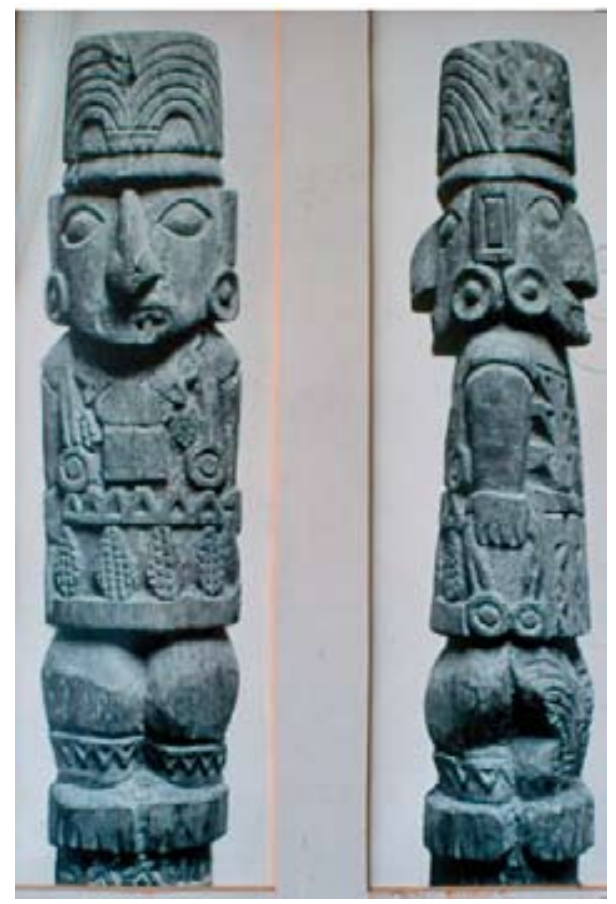

Figura 3. La imagen de madera que representa al dios Pachacámac. Museo de sitio en Pachacámac.

The wooden image that represents the god Pachacámac. Archaeological Site Museum of Pachacámac. 
Curiosamente a orillas del lago Titicaca hay varios ídolos bifrontes, alguno de ellos descrito como dios de las comidas.

\section{Pachacámac en el Collasuyo}

Potosí queda muy lejos del santuario de Pachacámac que está situado cerca de Lima, nosotros suponemos que en ruta tan larga debieron quedar algunos indicios; los encontramos en Ilabe y Copacati a orillas del lago Titicaca, entre los kallahuayas al norte de La Paz, en el salar de Uyuni y finalmente en Potosí.

Entre Chucuito y Puno está Ilabe donde, según Arriaga, había en un cerro cercano:

una plazuela hecha a mano, y en ella una estatua de piedra labrada con dos figuras monstruosas la una de varón, que miraba al nacimiento del sol, y la otra con rostro de mujer a las espaldas que miraba al Poniente... Las cuales figuras tienen unas culebras gruesas que suben del pie a la cabeza a la mano derecha e izquierda, y así mismo tienen otras figuras de sapos (Arriaga 1968:227-228).

El ídolo que encontró Arriaga estaba enterrado hasta la cintura.

Ramos Gavilán (1988 [1621]) nos dice que a poca distancia de Ilabe el año de 1619, el cura García Cuadrado encontró sobre el cerro Tucumu, que está entre los pueblos de Ilabe y Juli

un ídolo de piedra de tres varas y media de alto que tenía dos rostros, casi a la traza en que pintaron a Jano, salvo que el un rostro era de varón, y el otro de mujer, con dos culebras que subían de los pies y en la corona un sapo... Adorábanle por dios de las comidas (Ramos Gavilán 1988 [1621]:197).

Otra estela de las mismas características es la de Mocachi, también a orillas del lago Titicaca (Portugal Ortiz 1998:88, 89, 93). Las descripciones de Arriaga y de Ramos Gavilán son tan parecidas que quizá se trata de un mismo ídolo, enterrado por García Cuadrado y redescubierto por Arriaga.

Otro ídolo bifronte estudiado por Chávez y Mohr es el de Taraco, pueblo situado al noreste de Puno (Figura 4). Esta estela que dio lugar a la tipología que Chávez llama el estilo "Yaya-mama" tiene $1,75 \mathrm{~m}$ de altura y también es bifronte con serpientes en los costados. Un lado es femenino y otro masculino (Chávez y Mohr 1975).

Finalmente tenemos el relato de Gutiérrez de Santa Clara (1521-1603) que nos dice que a orillas del lago Titicaca se rendía culto a Pachacámac. Este autor indica que los indígenas esperaban el retorno de los dioses andinos, los cuales eran recibidos con danzas y borracheras, por lo que suponemos que se refiere a lo que Molina y Albornoz (citado en Millones 1990:12) llaman "la enfermedad de la danza" conocida como Taqui Oncoy (Gisbert 1999:59-63). El sacrificio involucra a Pachacámac y al Sol, y hace mención del Inca Viracocha como la persona que inicia este ritual. Gutiérrez de Santa Clara relata el sacrificio en estos términos:

cuando Viracocha Inga octavo, rey del Cuzco mandó a todos los curacas y principales

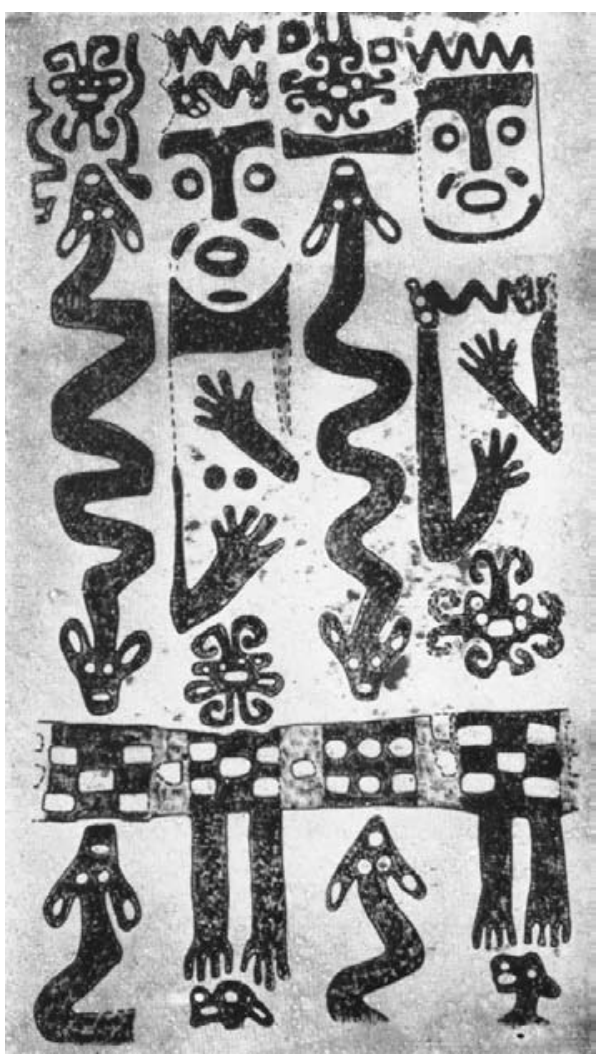

Figura 4. Esquema de la estela de Taraco, del estilo yaya-mama, según Chávez y Mohr (1975).

Scheme of the stela of Taraco, in the yaya-mama style, according to Chávez and Mohr (1975). 
indios que en cada año hiciesen en su memoria ciertos sacrificios al dios Sol su padre, porque rogase al dios Pachacama le perdonase los males que había hecho en este mundo contra su deidad, mandó que después de hechos estos sacrificios al Sol hiciesen otros a las furias infernales,... (Gutiérrez de Santa Clara 1963: T.III: 232-233).

En este primer párrafo hay que considerar el establecimiento de un doble sacrificio al Sol y a Pachacámac ya que por furias infernales tenemos que entender el mundo subterráneo. Este autor añade:

Por tanto, luego hacían gran llamamiento de todos los indios (e) indias, y...allí todos juntos bailaban y cantaban... y luego al otro día por la mañana hacían todos una gran borrachera con muchos sacrificios malos y horrendos, invocando al demonio porque no llevase al Inga a su región tartárea...

Este párrafo determina un doble culto, subterráneo a Pachacámac y celeste al Sol. Para ello enviaban un "mensajero"

ofrecíanse luego dos o tres indios borrachos, los que eran mas entendidos... echaban los ojos en el mas fuerte y bien razonado al cual hacían vestir muy ricamente unas ropas muy blancas de algodón y le ponían muchas axorcas, brazaletes, anillos... que todo era de oro fino... Puestas estas cosas le hacían estar en pie... y venía luego un indio de grandes fuerzas el cual traía una buena cachiporra de encina y cobre, para dalle... (con) gran fuerza un terrible golpe en la cabeza... luego le secundaban con otro golpe y lo acababan de matar...

La descripción es tan puntual que parece fue recibida por Gutiérrez de Santa Clara de un testigo presencial, no resulta fácil aceptar que el cronista, dado su carácter de español, hubiera presenciado el sacrificio. A continuación aclara:

Destos indios que así enterraban vide sacar la osamenta de dos dellos en el
Gran Collao... el un indio destos (sacrificados) sacó de la sepultura Don Martín de Guzmán, en el pueblo de Chucuito, y el otro sacó Don Francisco de Villacastín en Puno.

Estos testimonios nos permiten suponer que se rendía culto a Pachacámac en Taraco, Puno, Ilabe y Chucuito, todos pueblos situados a orillas del lago Titicaca.

En el norte departamento de La Paz (Bolivia) viven los kallahuayas, que aún hoy son médicos itinerantes. Oblitas Poblete señala que entre sus dioses se menciona Pachacámac. El texto dice: "El Pacha Tata es el dios Inti, lo llaman también Pacha qaman. Pacha Tata gobierna en el cielo... su esposa y hermana a la vez es Pachamama..." (Oblitas Poblete 1963:121y ss). Tiene un relato relativamente largo sobre este dios que sólo coincide en una pequeña parte con lo que conocemos de Pachacámac. En todo caso es un indicio de que este dios también se conocía en esta zona.

Si vamos más al sur tenemos un testimonio entre Oruro y el norte de Potosí, en el Salar de Uyuni, se trata de una tradición oral que recogí el año 2004. Fui al pueblo de Uyuni y al salar de este nombre con motivo de un festival turístico; se me acercaron dos señoras pidiéndome consiguiese que el Presidente de Bolivia escuchara una pieza teatral que ellas habían compuesto en base a la leyenda del lugar. Las señoras eran profesoras del "Colegio Antofagasta" de Uyuni y respondían a los nombres de Mary Ramos y Cándida Lisida. Como era imposible que se representara la pieza completa, llamada "Leyenda de Cachipampa", optaron por ofrecer algunos diálogos y me entregaron el guión que llevaban consigo del que extracto lo principal:

Excelentísimo Señor Presidente, con la venia de ud. y de todos los presentes, en esta ocasión el Colegio "Antofagasta" realizará la representación escénica de la Leyenda de Cachipampa, donde nos relata que en tiempos remotos las montañas que circundan eran como nosotros los hombres que habitaban y obedecían los mandatos de PACHACAMAC, el Padre Mundo. Entre las montañas poderosas cuenta la leyenda que Cuzco contrajo matrimonio con Tunupa, protagonista principal quien era 
de origen humilde, sin muchas riquezas, pero muy hermosa, con altos (sic) morales y espirituales. La infidelidad de Cuzco, los sufrimientos de Tunupa culminaron en los amoríos indisimulados de aquél con una adolescente ñusta llamada Ckosuña (continúa con un diálogo entre Cuzco y Ckosuña).

Cuzco de carácter arbitrario y despótico e infiel terminó con la felicidad de su matrimonio con Tunupa, quien le hizo comparecer ante el MUNDO, el curaca de alta autoridad (continúa con un diálogo entre Cuzco, Tunupa y el "Mundo").

El cielo se cubrió de nubes tempestuosas, los montes en furioso choque, hacían repercutir con sordo derrumbe la caída de sus rocas. Pasada la tormenta ante la ruptura de Cuzco y Tunupa, Tunupa se fue llorando por la pampa, caminó todo el día, debilitada por el cansancio, se quedó dormida y al despertar vio que del seno de la tierra, surgía PACHAMAMA su bondadosa madre (continúa con un diálogo entre Tunupa y Pachamama).

Al predecir y consolar a su hija, PACHAMAMA la madre tierra, desapareció. Tunupa quiso moverse, pero no pudo, pues se convirtió en montaña, lloró tanto que sus lágrimas fueron formando un lago que mezclado con la leche que emanaba de sus turgentes senos se iba mezclando hasta formar EL LAGO SAGRADO. Dicen que hasta el día de hoy, sigue llorando para ir acrecentando el lago de sal, actualmente el gran SALAR DE UYUNI, considerado maravilla del mundo.

El diálogo entre Tunupa y la Pachamama se resume así:

PACHAMAMA le dijo (a TUNUPA) que ella ya se había enterado que el padre de todos, PACHACÁMAC, había castigado al soberbio Cuzco quitándole todas sus riquezas las que serán trasladadas al Sumac-Orco en sus vicuñas, y que Kosuña por haber sido infiel guardaría todas sus riquezas en su corazón, y los humanos para extraerla tendrían que sufrir...
Podemos indicar que a través de esta leyenda se constata que en los pueblos aledaños al salar de Uyuni se mantiene la tradición de que en un momento dado Pachacámac fue considerado señor de todos los dioses y que en el Sumac-Orco (cerro de Potosí) se recogían y guardaban sus riquezas. En la recopilación de estas profesoras, donde los personajes son Pachacámac, Pachamama, Tunupa, el Mundo y el Cuzco, todos ellos están enlazados por una figura creada para relato que es Ckosuña. Hay en esta obra todo tipo de interferencias, el Mundo recuerda los Autos Sacramentales españoles, el Cuzco nos recuerda la presencia de los incas en esta zona, y quedan tres figuras míticas: Pachacámac (relacionado con el Cerro de Potosí), Pachamama diosa de la tierra, y Tunupa que es un dios de la zona del Collao el cual muere en la isla del Sol. Es atado su cuerpo a una barca que es arrojada al lago, al chocar ésta con la orilla sur-este abre el río Desaguadero, que une el lago Titicaca con el Poopó, allí la barca se hunde y Tunupa reaparece en el Salar de Uyuni trasformado en volcán (Gisbert 1980:35-39). Una leyenda de esta zona, recogida por Wachtel (2001), presenta la imagen de Tunupa como una mujer que es disputada por dos volcanes: el Sajama y el Sabaya. Tunupa, a su vez, también queda convertida en volcán, el cual está a orillas del salar (Wachtel 2001:521-522). Wachtel nos dice que este relato es conocido en todo Carangas (provincia del departamento de Oruro). Ramiro Molina es quien recoge la leyenda de que el salar se formó con la leche de Tunupa (Molina 1989). Finalmente debo agradecer a Pablo Quisbert el indicarme que Tunupa, Cuzco, Cosuña y Mundo son cerros cercanos al Salar de Uyuni.

\section{Los Apus y la Virgen María}

El culto a la Madre Tierra fue uno de los escollos fundamentales para la cristianización del sur andino, escollo que trató de salvarse con la identificación de la Pachamama con la Virgen María. Es necesario leer a Alonso Ramos Gavilán (1988 [1621]) para comprender el proceso de sincretismo que lleva a esta identificación. El cronista nos dice:

Dios (es) el padre que produce la vida, (y) porque ningún bien llegue a la tierra sin que se deba a la Virgen, deposita en ella 
los rayos de su poder, para que después ella, como madre, los comunique a la tierra (Ramos Gavilán 1988 [1621]:184).

Aquí la identificación de María con la Madre Tierra es evidente. Por otra parte, los doctrineros deseaban terminar con la dispersión de los numerosos dioses englobándolos en imágenes cristianas unificadoras como se hizo con la Virgen que al identificarse con la tierra engloba en ella a los apus o cerros sacralizados. Otro texto del mismo Ramos Gavilán dice: "María es el monte de donde salió aquella piedra... que es Cristo". Para este autor Cristo es piedra reluciente, o diamante. Este complicado símil permite imaginar a la Virgen como monte de piedras preciosas (o metal precioso), razón por la que se identifica a María con el Cerro de Potosí.

El proceso es doble, por un lado está la identificación de María con la Pachamama, y por otro, la superposición de la Virgen sobre aquellos cerros que eran adorados como huacas sagradas. Son los apus, dioses masculinos que forman parte de la Pachamama en una extraña dualidad andrógina. La Virgen María cristianiza al Cerro, ella como madre, como Pachamama, es el lado positivo de este adoratorio que cobija al terrible Pachacámac, convertido hoy en el "tío" de nuestro folclore.

En tiempos virreinales fue representada la Virgen María como "madre tierra" en forma explícita; el ejemplo más importante es el cuadro existente en el museo de la Moneda (Potosí) donde María y el Cerro de Potosí son un todo. En el lienzo se muestra la montaña con rostro femenino y un par de manos con las palmas abiertas. Es la imagen de María inserta en el cerro y coronada por la Trinidad. Al pie pueden verse el papa Pablo III, un Cardenal y un Obispo; al lado opuesto, Carlos V y un indígena cuya capa ostenta la cruz de Alcántara, seguramente se trata de un cacique donante. Todos están de hinojos y ante ellos el mundo. En la falda del cerro está el Inca Maita Cápac, el cual según algunos historiadores, es quien conquistó el Collasuyo; versión inexacta pero muy popular (Figura 5).

En un lienzo con la misma composición, fechado en 1720, hoy en el Museo Nacional de Arte (La Paz) el Emperador Carlos V y el papa Pablo III fueron sustituidos por el papa y el monarca correspondientes. Existen un total de cinco composiciones sobre este asunto, lo que indica

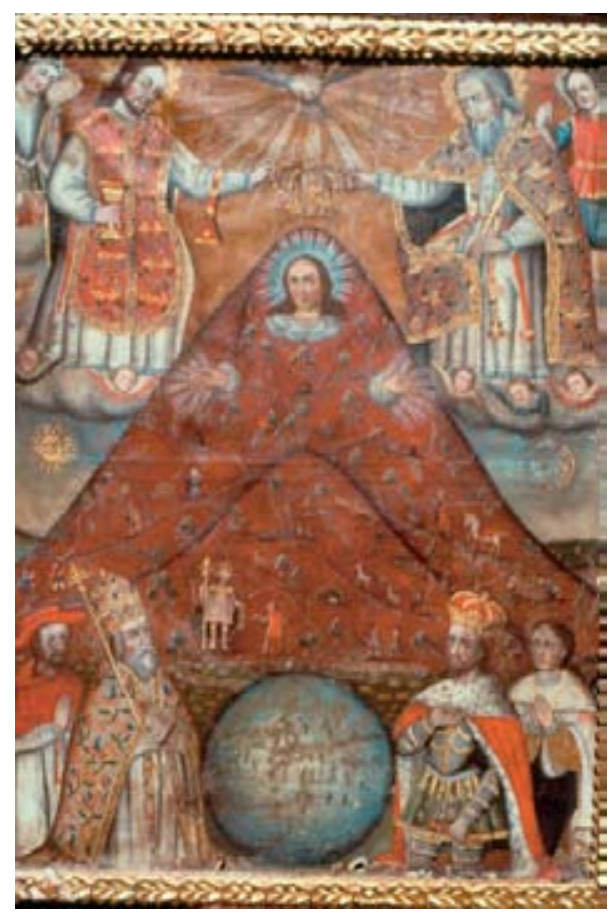

Figura 5. Anónimo. La Virgen-Cerro. Museo de la Moneda, Potosí.

Anonymous. The Virgen-Cerro. Mint Museum, Potosí.

que estamos ante una iconografía establecida y divulgada (Gisbert 1980:17).

Las pinturas potosinas sobre el tema muestran en dos casos la coronación de la Virgen, por ello sabemos que estamos ante la advocación de María Reina. La documentación de comienzos del siglo XVII afirma que el Cerro de Potosí fue adorado bajo la denominación de "Reina", por los indígenas. Las Relaciones Geográficas de Indias (Jiménez de la Espada 1965) confirman que el cerro de Potosí era objeto de culto y que se lo denominaba "reina", así en ellas se dice:

el Cerro Rico que se llama Potoschí, de una muy hermosa hechura, que parece hecha de mano... y por esto, o porque a las minas llaman COYA en lengua de los indios, que quiere decir REINA llaman a este cerro por excelencia REINA.

Aquí es clara la identificación del Cerro de Potosí con María Reina, ya que tanto a la Virgen como al cerro se los denomina Coya. Este concepto 
es el que se plasma en el lienzo de María-Cerro, coronada por la Trinidad.

Ramos Gavilán (1988 [1621]) en su texto crea la teoría que permite identificar a María con un monte. Este mito emigra de las orillas del lago Titicaca a Potosí, dejando a su paso una estela de Vírgenes superpuestas a los apus o montes que habían recibido culto en tiempos prehispánicos, buen ejemplo de esto son Pucarani y Sabaya, ambas fundaciones agustinas.

De la identificación de María con un monte, sustentada teológicamente, a la identificación de María con la Pachamama solo hay un paso y el proceso se dio tanto a nivel rural y popular como a nivel erudito-eclesiástico, lo que implica eliminar a los dioses menores y dispersos en beneficio de una sola divinidad. Por eso María engloba en sí muchas cosas, entre ellas a la Madre Tierra y por ende el espíritu de las montañas.

La Virgen más conocida después de la de Copacabana es la que Tito Yupanqui hizo para Pucarani, donde los agustinos para desterrar el culto gentílico que allí se practicaba, la entronizaron. Al respecto Alcedo (1967) en su Diccionario dice, refiriéndose a Pucarani:

adoraban estos gentiles un cerro que sobresale entre los demás de la cordillera y es el inmediato al pueblo, llamado Cacaaca... donde tenían la figura de un indio de piedra, de media vara de alto, sacrificando criaturas para aplacarlo

y añade:

se ha hecho célebre (Pucarani) por la milagrosa imagen de Nuestra Señora de la Candelaria con la advocación de Gracia...y la colocaron el año de 1589... la cual hizo por el modelo de la de Copacabana Don Francisco Tito Yupanqui, indio de sangre real... (Alcedo 1967 TIII: 241).

Del texto se deduce que la Virgen fue entronizada para sustituir al cerro Caacaca y a su ídolo. Dicho cerro es el actual Huayna Potosí en el departamento de La Paz.

Al sur de la región de Carangas, en el actual departamento de Oruro, se venera el cerro Sabaya (Gisbert 1980:22 y ss). Es un volcán apagado del cual se recuerda estuvo activo (Figura 6). Históricamente se sabe que en el siglo XVII el pueblo edificado a los pies del Sabaya desapareció. Es posible que la erupción del Sabaya sea coincidente con la del Omate. Los agustinos entronizaron la Virgen de la Candelaria en Sabaya para sustituir el culto al volcán. El santuario tuvo su apogeo en el siglo XVIII, cuando el pintor indio Luís Niño divulga, por medio de sus cuadros, la imagen de la Virgen de Sabaya (Figura 7).

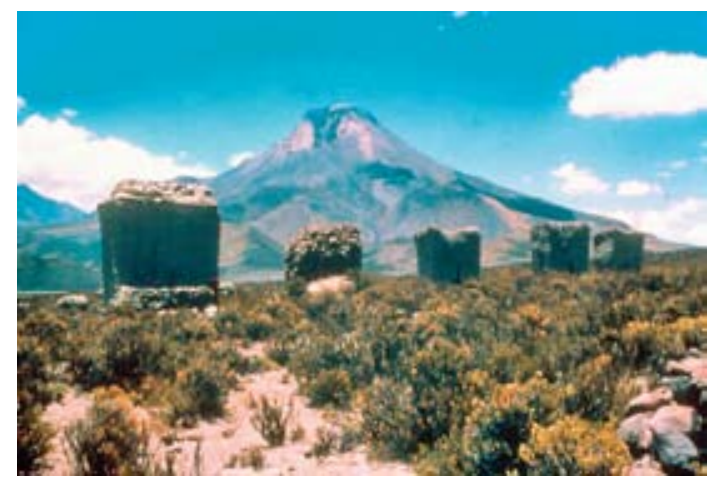

Figura 6. Vista del volcán Sabaya, Departamento de Oruro. View from the Sabaya Volcano, Departament of Oruro.

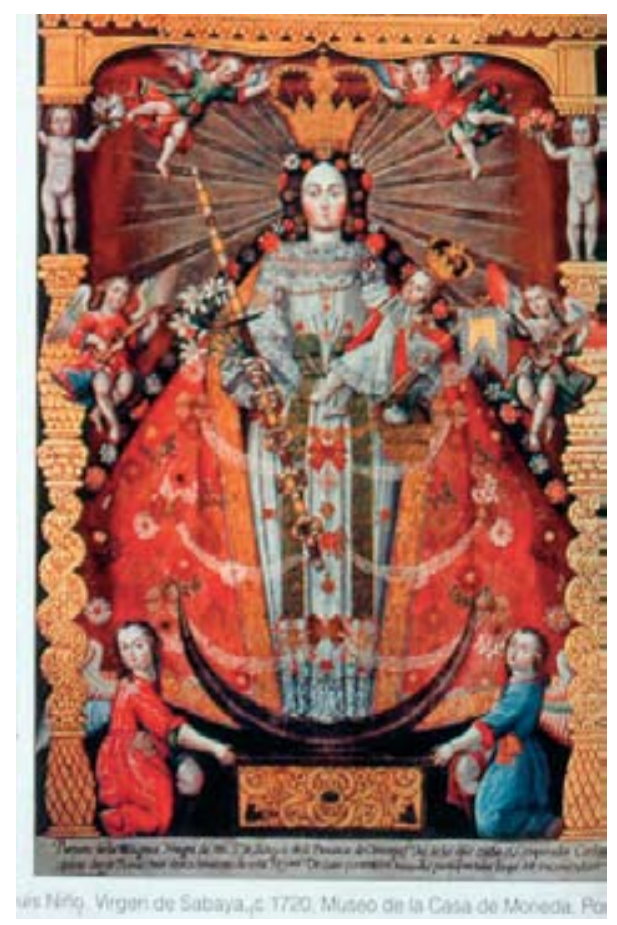

Figura 7. Luís Niño. La Virgen de Sabaya que sustituye al volcán de su nombre. Adorado por los indios Carangas. Museo de la Moneda, Potosí.

Luís Niño. The Virgin of Sabaya who substitutes the volcano that carried her name. It is adored by the Carangas Indians (Mint Museum, Potosí). 


\section{Conclusión}

Por lo anotado debemos considerar que el Cerro de Potosí era una huaca y que como tal la adoraban. Según Arzans de Orsúa y Vela esta huaca estaba relacionada con el dios Pachacámac, quien deja huellas en todo el Collao, pues quedan indicios de su presencia en el norte de La Paz (entre los kallahuayas), a orillas del lago Titicaca, y en Uyuni, este hecho indica que Pachacámac era conocido y adorado en el Collasuyo.

EL cerro de Potosí, que según Ocaña estaba dedicado al Sol y a Pachacámac según Arzans de Orsúa y Vela, se nos muestra con doble faz, recordándonos así el mito de Pachacámac y Vichama con el antagonismo y la complementariedad entre el dios del día y el dios de la noche. Algo similar parecen decir las estelas Yaya-Mama en torno al lago Titicaca y el sacrificio hecho cerca de Chucuito donde se invoca conjuntamente al Sol y a Pachacámac.

Por otra parte, los doctrineros identifican al Cerro de Potosí con la Virgen María borrando la huella del antiguo dios bifronte, como también identifican a María con los cerros de Pucarani y Sabaya. La Virgen es un elemento globalizador que elimina la dispersión de cultos, más, si reconocemos en ella una identidad con la Madre Tierra (o Pachamama). Como lo sugiere Ramos Gavilán, la Madre Tierra cobija en sí a todos los apus, opacando el recuerdo del dios específico al que cada uno de estos estaba consagrado. En el caso de las minas bolivianas estos apus se convierten en el "Tío", y en el Perú en el "Muqui". Ambos son figuras subterráneas que señorean el averno.

Finalmente varios mitos relacionan al Sol con Pachacámac y también a la Pachamama con Pachacámac, ésta como esposa o hermana del dios bifronte.

Agradecimientos: a María Rostworowski, con admiración y respeto por su trabajo, y mi agradecimiento por haber evaluado mi artículo, asimismo mi agradecimiento al evaluador anónimo, y a ambos por sus valiosas indicaciones.

\section{Referencias Citadas}

Alcedo, A.

1967 Diccionario Histórico y Geográfico de las Indias Occidentales de América. T. III. Biblioteca de Autores Españoles, Madrid.

Arzans de Orsúa y Vela, B.

1965 [1736] Historia de la Villa Imperial de Potosí. 3 vol, editado por L. Hanke y G. Mendoza. Brown University Press, Providence.

Calancha, A. de la

1976 [1638] Coronica Moralizada de la Provincia del Perú de la Orden de S. Agustín. 6 vol. Edición Prado Pastor, Lima.

Capoche, L.

1959 [1585] Relación General del Asiento y Villa Imperial de Potosí y de las Cosas más Importantes a su Gobierno. Biblioteca de Autores Españoles, Madrid

Cobo, B.

1956 Historia del Nuevo Mundo. 2 vol. Biblioteca de Autores Españoles, Madrid.

Chávez, S. y K. Mohr

1975 A carved stela from Taraco, Puno (Perú) and the definition of an early style of stone sculpture from the altiplano of Perú and Bolivia. Ñaupa Pacha 13:45-84.

Eeckhout, P.

2004 Reyes del sol y señores de la luna. Inkas e Ychmas en Pachacámac. Chungara Revista de Antropología Chilena 36:495-503.

Egaña A. S.J.

1974 Monumenta Peruana T. IV. Institutum Historicum Societatis Iesu. Roma
Gisbert, T.

1980 Iconografía y Mitos Indígenas en el Arte. Ed. Gisbert, La Paz.

1999 El Paraíso de los Pájaros Parlantes. Ed. Plural, La Paz.

Gutiérrez de Santa Clara, P.

1963 Historia de las guerras civiles del Perú. En Crónicas del Perú. Tomo III, Biblioteca de Autores Españoles, Madrid.

Jiménez de la Espada, M, editor

1965 Relaciones Geográficas de Indias. 2 vol. Biblioteca de Autores Españoles, Madrid.

Mateos, F. SJ., editor

1944 Crónica Anónima de 1600 que Trata del Establecimiento y Misiones de la Compañía de Jesús. 2 vol. Instituto Fernández de Oviedo, Madrid.

Menzel, D.

1968 La Cultura Huari. Ed. Compañía de Seguros PeruanosSuiza S.A., Lima.

Millones, L., compilador

1990 El Retorno de las Huacas. IEP, Lima.

Molina, R.

1989 La leyenda de la Tunupa. Revista Encuentro 5:42-51, La Paz.

Oblitas Poblete, E.

1963 Cultura Callawaya. Talleres Gráficos Bolivianos, La Paz.

Ocaña, D. de

1969 [1601] Un Viaje Fascinante por la América Hispana. Edición Arturo Álvarez, Madrid. 


\section{Portugal Ortiz, M.}

1998 Escultura Prehispánica Boliviana. UMSA, La Paz.

Platt, T., T. Bouysse-Cassagne y O. Harris 2006 Qaraqara-Charca. Ed. IFEA-Plural, La Paz.

Ramos Gavilán, A.

1988 [1621] Historia del Célebre Santuario de Ntra. Sra. de Copacabana e Invención de la Cruz de Carabuco. Edición Ignacio Prado P., Lima.

Rostworowski, M.

1992 Pachacámac y el Señor de Los Milagros. IEP, Lima.
Salazar-Soler, C.

1997 Las Huacas y el conocimiento científico en el siglo XVI: a propósito del descubrimiento de las minas de Potosí. En Saberes y Memorias en los Andes. In Memoriam Thierry Saignes. Creedla-IFEA, Lima.

Taylor, G.

1987 Ritos y Tradiciones de Huarochiri. IFEA, Lima.

Wachtel, N.

2001 El Regreso de los Antepasados. Los indios Urus de Bolivia, del Siglo XX al XVI. Fondo de Cultura Económica, México. 